\title{
Synthesis of Branched Silicon-Containing Arylethyleneacetylene Resin and the Performance of Casting
}

\author{
Yusheng Chen, Xintong You, Shifeng Deng
}

Key Laboratory of Specially Functional Polymeric Meterials and Related Technology of the Ministry of Education ECUST, Shanghai, China

Email: 1468560637@qq.com

How to cite this paper: Chen, Y.S., You, X.T. and Deng, S.F. (2018) Synthesis of Branched Silicon-Containing Arylethyleneacetylene Resin and the Performance of Casting. Journal of Materials Science and Chemical Engineering, 6, 1-7. https://doi.org/10.4236/msce.2018.670 $\underline{01}$

Received: May 15, 2018

Accepted: July 1, 2018

Published: July 4, 2018

\begin{abstract}
With good thermal properties, dielectric property and high-temperature ceramics performance, silicon-containing arylacetylene resin (PSA) has opened an attractive alternative to high performance thermosetting resins in application in the area of aircraft and missile. However, it is difficult to introduce silicon into the main chain of organic arylacetylene. In this paper, branched silicon-containing arylethyleneacetylene (BSA) resin was synthesized by methyltrichlorosilane and diethynylbenzene with zinc powder as catalyst. The advantages lie in simple operation, short reaction period and mild heat release. BSA resin exhibits excellent processability with the processing temperature of $20^{\circ} \mathrm{C}-150^{\circ} \mathrm{C}$ and processing window of $130^{\circ} \mathrm{C}$. The glass transition temperature of the resin casting is over $500^{\circ} \mathrm{C}$. The temperature of $5 \%$ weight loss $\left(T_{\mathrm{d} 5}\right)$ is up to $575^{\circ} \mathrm{C}$ and char yield of thermoset at $800^{\circ} \mathrm{C}\left(Y_{800}\right)$ reaches $91 \%$ under nitrogen. Also, the dielectric constant and dielectric loss of casting has no change within $10-10^{6} \mathrm{~Hz}$.
\end{abstract}

\section{Keywords}

Branched Silicon-Containing Arylethyleneacetylene (BSA), Zinc Powder, Processability, Heat-Resistant Material

\section{Introduction}

Since 20th century, many countries have strived to develop aviation industry. The development of aviation technologies can reflect the comprehensive strength of a country. The friction between aviation aircraft and atmosphere while high-speed flying will raise the surface temperature, which leads to high requirements on the thermal property of materials [1]. Many heat resistant materials with special functions are widely used on the aerospace vehicle [2]. 
In recent years, PSA resin has attracted much attention from international and domestic academics. The introduction of silicon improve the thermal stability [3], high-temperature ceramization performance [4] [5] and dielectric property [6]. The main challenge in the synthesis of PSA is how to introduce the organic silicon into the chain segment of arylacetylene polymer. Itoh $\mathrm{M}$ [7] used phenylsilane and 1,3-diethynylbenzene catalyzed by $\mathrm{MgO}$ synthesized the poly[(phenylsilylene)ethynylene-1,3-phenyleneethynylene] (MSP). Jiang $\mathrm{H}$ [8] et al. used zinc chloride catalyzed polycondensation reaction of diethynylbenzene and aminosilane, and synthesized PSA resin containing terminal amino group. This reaction is quick and has high yield, but the terminal amino group impairs the thermal stability of resin. Zhou Q [9] et al. first prepared lithium phenylacetylide from the reaction of phenyl acetylene and butyllithium, then this compound was further reacted with methyltrichlorosilane to obtain MTPES. MTPES has good thermal stability, yet the synthesis has large heat release and the reaction system is unstable.

In this article, we prepared branched silicon-containing arylethyleneacetylene resin (BSA) by diethynylbenzene and methyltrichlorosilane catalyzed by zinc power. The molecular weight of BSA resin is easy to control, the reaction process is simple, and there is no heat released; the crosslinking density of thermoset is higher, and thermoset has better thermal property; terminal olefinic on the molecular chain reduces the viscosity of resin which improving the processability of resin.

\section{Experimental}

\subsection{Materials}

Diethynylbenzene (DEB, purity $>98 \%$, prepared by Shanghai Like Chemical Technology Co., Ltd.); Methyltrichlorosilane (MTS, purity $>98 \%$, purchased by Acros Organics); zinc powder (AR, bought from Sinopharm Group); acetonitrile (AR), toluene (AR), hydrochloric acid (AR), acetone (AR) were purchased by Lingfeng Chemical Reagent Co., Ltd.

\subsection{Synthesis of BSA}

An nitrogen-flushed $250 \mathrm{~mL}$ three-necked reaction vessel equipped with a reflux condenser, an addition funnel, and a stirring motor was dried. Added zinc powder $(0.3 \mathrm{~mol})$ and $40 \mathrm{~mL}$ acetonitrile, then the mixed solution of DEB $(0.1 \mathrm{~mol})$ and $20 \mathrm{~mL}$ acetonitrile was added slowly with stirring within 10 minutes. When the temperature rose to $56^{\circ} \mathrm{C}$, dropwise added the mixed solution of DEB $(0.1 \mathrm{~mol})$ and $20 \mathrm{~mL}$ acetonitrile with stirring within 20 minutes. After finished the addition, the mixture was stirred at $80^{\circ} \mathrm{C}$ for 10 hours.

After the reaction finished, the solution was filtered to separate out the zinc chloride and excess zinc powder. The filtrate was diluted with $80 \mathrm{~mL}$ toluene, then added with deionized water to dissolve the $\mathrm{ZnCl}_{2}$ generated in the reac- 
tion for three to five times. Then separated water and upper organic phase, after evaporation of solvent, pure BSA resin was isolated by distillation under reduced pressure. The reaction scheme is shown in Figure 1.

\subsection{Synthesis of BSA}

To remove any volatile material, the sample was heated at $100^{\circ} \mathrm{C}$. The sample was placed in a furnace and cured at $150^{\circ} \mathrm{C} / 2 \mathrm{~h}, 170^{\circ} \mathrm{C} / 2 \mathrm{~h}, 210^{\circ} \mathrm{C} / 2 \mathrm{~h}$, and $250^{\circ} \mathrm{C} / 4 \mathrm{~h}$

\subsection{Synthesis of BSA}

The viscosity of the resin was analyzed by rotary viscosimeter. Broadband dielectric impedance spectrometer were used to analysis the dielectric properties of thermoset. The dynamic mechanical properties of thermoset were measured by means of dynamic mechanical analysis methods.

\section{Results and Discussion}

\subsection{Reaction Conditions}

Different solvents were used as reaction solvent to explore the influence on this reaction. We used $0.1 \mathrm{~mol}$ DEB, $0.033 \mathrm{~mol}$ DCMS and $0.3 \mathrm{~mol}$ zinc powder in this reaction, and proceed $10 \mathrm{~h}$ at $80^{\circ} \mathrm{C}$. The results are shown in Table 1. We can know from the table that only when acetonitrile serves as the reaction solvent can the reaction going on, while other solvents cannot.

Acetonitrile as reaction solvent, react $10 \mathrm{~h}$ at $80^{\circ} \mathrm{C}$, different dosage of zinc powder were used to explore effect on the reaction yield. The results are shown in Table 2 . When the dosage of zinc powder was $0.1 \mathrm{~mol}$, the yield was $40.1 \%$; when the dosage of zinc powder increased to $0.2 \mathrm{~mol}$, the yield was

$8 \%$

w h e n

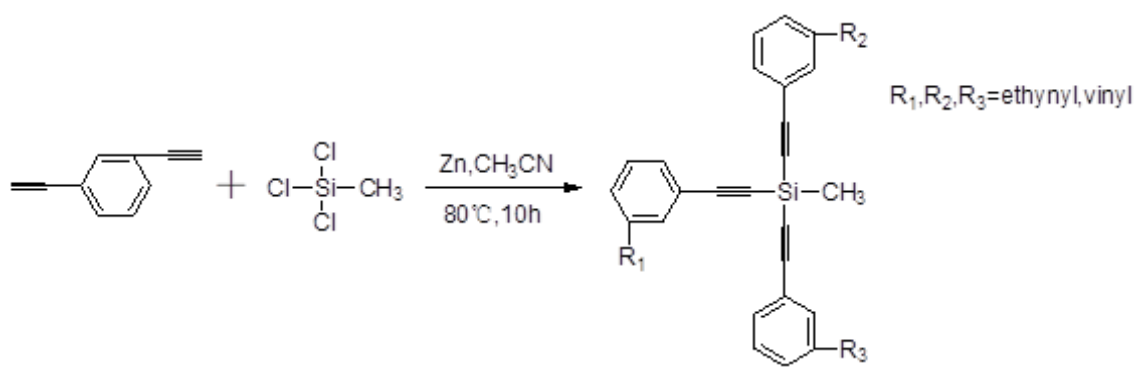

Figure 1. The reaction scheme of BSA resin.

Table 1. Effects of different solvents on reactions.

\begin{tabular}{cccccc}
\hline Solvents & Acetonitrile & Tetrahydrofuran & Toluene & $\begin{array}{c}\text { Dimethyl } \\
\text { sulfoxide }\end{array}$ & $\begin{array}{c}\text { Dimethyl } \\
\text { formamide }\end{array}$ \\
\hline $\begin{array}{c}\text { Temperature }\left({ }^{\circ} \mathrm{C}\right) \\
\text { Reaction result }\end{array}$ & $\begin{array}{c}80 \\
\sqrt{ }\end{array}$ & $\begin{array}{c}66 \\
\times\end{array}$ & $\begin{array}{c}100 \\
\times\end{array}$ & $\begin{array}{c}100 \\
\times\end{array}$ & $\begin{array}{c}100 \\
\times\end{array}$ \\
\hline
\end{tabular}

Note: " $x$ " means no reaction; " $\sqrt{ }$ " means has reaction.

Table 2. Effects of zinc amounts on reaction yields. 


\begin{tabular}{cccc}
\hline Zinc (mol) & Temperature $\left({ }^{\circ} \mathrm{C}\right)$ & Time $(\mathrm{h})$ & Yield (\%) \\
\hline 0.1 & 80 & 10 & 40.1 \\
0.2 & 80 & 10 & 49.8 \\
0.3 & 80 & 10 & 78.2 \\
0.4 & 80 & 10 & 78.8 \\
\hline
\end{tabular}

the dosage of zinc powder was $0.3 \mathrm{~mol}$, the yield was $78.2 \%$; and when the dosage of zinc powder was $0.4 \mathrm{~mol}$, the yield was $78.8 \%$, there's no obvious improvement compared with $0.3 \mathrm{~mol}$. Considerate of the reaction yield, the optimal dosage of zinc powder is three times as much as DEB.

\subsection{Thermal Property}

The thermoset was prepared with curing process. The thermal property of thermoset was analysed by TGA, the spectrogram is shown in Figure 2. The results shown that the $T_{\mathrm{d} 5}$ of thermoset is $575^{\circ} \mathrm{C}$ in the nitrogen atmosphere, the $Y_{800}$ was $91 \%$, which indicates that BSA resin has high heat-resistant performance. However, BSA resin contains terminal olefinic, which degraded the thermal property of BSA resin. On the other hand, owing to the branched structure of BSA resin, the rate of ring formation was improved, thereby improving the crosslinking density of cured resin and thermal properties of BSA.

\subsection{Viscosity of BSA Resin}

The rheological property of resin is an important index reflecting the internal structure and processability. Exploring the rheological behavior has great significance for machining and shaping of resin.

Tested the rheological properties of BSA resin, rheological curve is shown in Figure 3. It is observed that when the temperature rose from $40^{\circ} \mathrm{C}$ to $150^{\circ} \mathrm{C}$, the viscosity of BSA resin does not change significantly. When the temperature rises to $150^{\circ} \mathrm{C}$, the viscosity of resin increases sharply, which is mainly due to the gelation of resin. BSA resin is flowable at room temperature, so the processing temperature of $\mathrm{BSA}$ resin is from $20^{\circ} \mathrm{C}$ to $150^{\circ} \mathrm{C}$, and the processing window is $130^{\circ} \mathrm{C}$. Therefore, the BSA resin has prefect processability.

This paper also tested the viscosity of BSA resin at $90^{\circ} \mathrm{C}$ as time goes on. The viscosity presented in Figure 4. We can see that the viscosity of BSA resin increases slowly over time at $90^{\circ} \mathrm{C}$. In the beginning, the viscosity of BSA resin is $336.2 \mathrm{mPa} \cdot \mathrm{s}$, and then changed to $650.3 \mathrm{mPa} \cdot \mathrm{s} 3$ hours later, which indicates that viscosity of BSA resin is relatively stable, so it can be used in processing temperature for long time.

\subsection{Properties of Casting}

Casting was prepared in a special mould using heating procedure, The diameter size of cylindrical casting is $30 \mathrm{~mm}$. The dielectric property of casting 


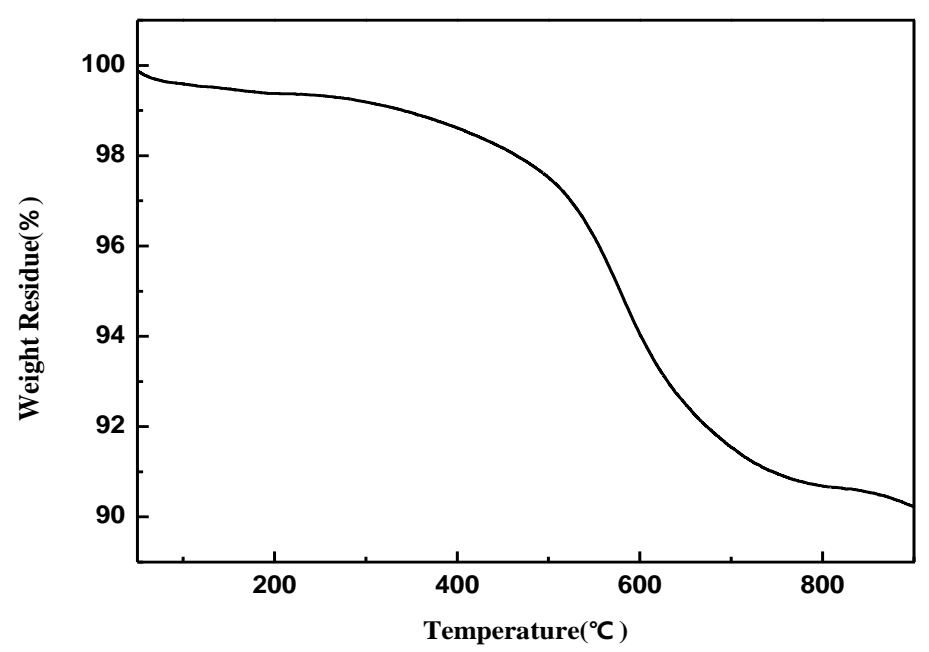

Figure 2. TGA curve of cured BSA resin in $\mathrm{N}_{2}$.

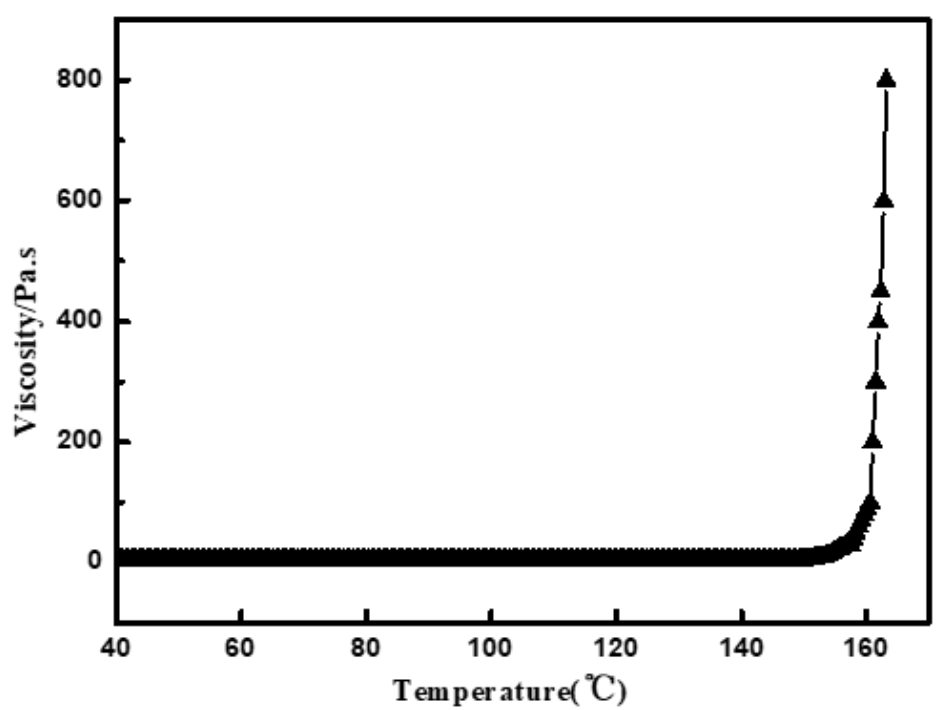

Figure 3. Viscosity vs temperature for BSA resin.

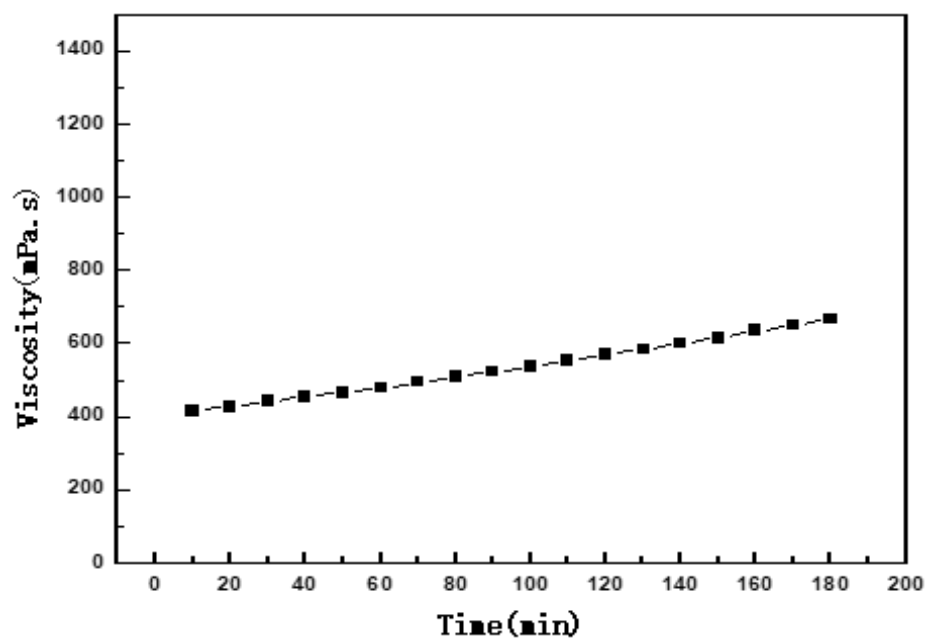

Figure 4. Viscosity of BSA resin at different time. 
investigated by broadband dielectric impedance spectrometer. The spectrum is shown in Figure 5. It is obviously that the dielectric constant $(\varepsilon)$ and dielec$\operatorname{tric} \operatorname{loss}(\tan \delta)$ is stable in the range of $10-10^{6} \mathrm{~Hz}$, which elucidates that casting has good dielectric property as a low-pole polymer.

Casting was prepared in special mould using heating procedure, the size of cuboid casting is $35 \mathrm{~mm} \times 6 \mathrm{~mm} \times 2 \mathrm{~mm}$. The viscoelasticity of casting was determined by DMA. The spectrogram of DMA is shown in Figure 6. We can see that within $50^{\circ} \mathrm{C}-500^{\circ} \mathrm{C}$, the storage modulus (E) and losses tangent $(\tan \delta)$ for the casting were little changed, implying that casting has no glass transition within $50^{\circ} \mathrm{C}-500^{\circ} \mathrm{C}$.

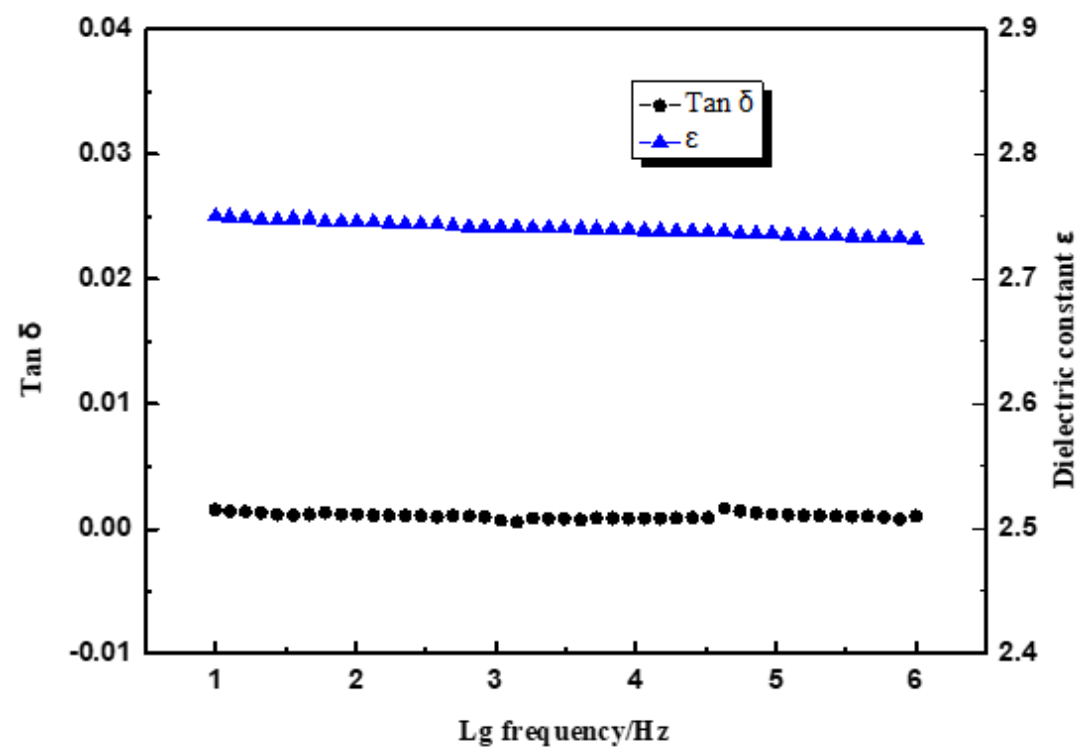

Figure 5. Dielectric curve of cured BSA resin.

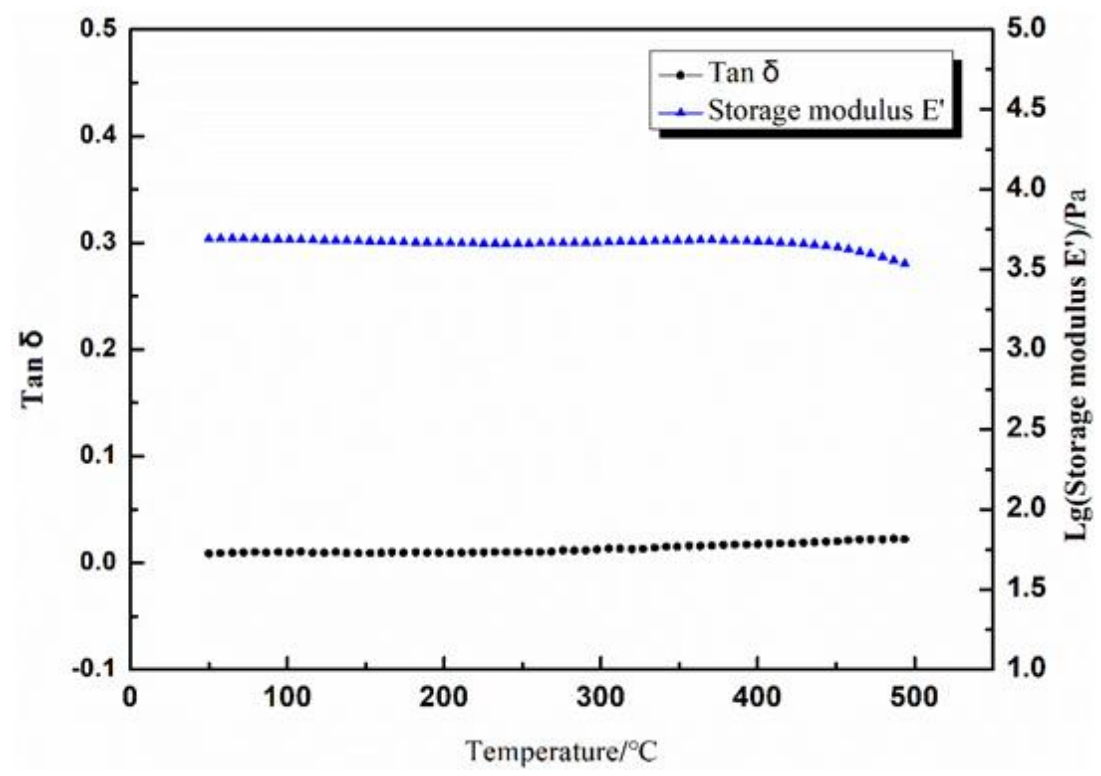

Figure 6. DMA curve of cured BSA. 


\section{Conclusion}

In this article, branched silicon-containing arylethyleneacetylene resin was synthesized by methyltrichlorosilane and diethynylbenzene catalyzed by zinc powder. The optimum conditions: acetonitrile as the reaction solvent, the amount of zinc overdosed $200 \%$. The reaction has advantages of simple operation, short reaction period and mild heat release. BSA resin has good thermal properties: $T_{\mathrm{d} 5}$ of thermoset reaches up to $575^{\circ} \mathrm{C}$, and $Y_{800}$ is $91 \%$. BSA resin has excellent processability. The dielectric constant and dielectric loss of the casting are stable within $10-10^{6} \mathrm{~Hz}$, which implies good dielectric properties, the glass transition temperature of the resin casting is over 500 ${ }^{\circ} \mathrm{C}$.

\section{References}

[1] Meador, M.A. (1995) High Temperature Polymer Matrix Composite for Aeropropulsion Appications. Materials Challenge Diversification and the Future, 268-276.

[2] Lin, S.C. and Pearce, E.M. (1994) High Performance Thermosets. Hanser, New York, 108.

[3] Zhang, J., Huang, J. and Du, W. (2011) Thermal Stability of the Copolymers of Silicon-Containing Arylacetylene Resin and Acetylene-Functional Benzoxazine. Polymer Degradation \& Stability, 96, 2276-2283. https://doi.org/10.1016/j.polymdegradstab.2011.04.022

[4] Wang, C., Huang, F., Jiang, Y., Zhou, Y. and Du, L. (2012) A Novel Oxidation Resistant SiC/B4, C/C, Nanocomposite Derived from a Carborane-Containing Conjugated Polycarbosilane. Journal of the American Ceramic Society, 95, 71-74. https://doi.org/10.1111/j.1551-2916.2011.04972.x

[5] Brefort, J.L., Corriu, R.J.P., Gerbier, P., Guerin, G. and Henner, B.J.L. (1992) New Poly[(Silylene)Diacetylenes]and Poly[(Germylene)Diacetylenes]: Synthesis and Conductive Properties. Orga-nometallics, 11, 2500-2506. https://doi.org/10.1021/om00043a037

[6] Yan, L., Zhang, X., Li, H. and Gui, H. (2007) Carbon Cloth Reinforced Polyarylacetylene Ablative Materials. Journal of Advanced Materials, 39, 22-25.

[7] Itoh, M. (1999) A Novel Synthesis of a Highly Heat-Resistant Organosilicon Polymer Using Base Catalysts. Catalysis Surveys, 3, 61-69. https://doi.org/10.1023/A:1019051113699

[8] Jiang, H., Deng, S.F. and Ruan, X.Z. (2017) Zinc Chloride Catalyzes Synthesis of Silicon-Containing Arylacetylene Resin. Polymer Materials Science and Engineering, 33, 18-21.

[9] Zhou, Q., Feng, X., Ni, L.Z. and Chen, J.D. (2006) Novel Heat Resistant Methyl -Tri(Phenylethynyl)Silane Resin: Synthesis, Characterization and Thermal Properties. Applied Polymer Science, 102, 2488-2492. https://doi.org/10.1002/app.24605 